\title{
Comparing the Effect of Face-to-Face with Phone Counselling Based on Cognitive-Behavioral Therapy on Vasomotor Symptoms in Postmenopausal Women: A Randomized Controlled Trial
}

Nasim Sadeghi Joola

Ahvaz Jondishapour University of Medical Sciences

Pourandokht Afshari ( $\sim$ poafshari@gmail.com )

Ahvaz Jondishapour University of Medical Sciences https://orcid.org/0000-0002-3383-9908

Maryam Gholamzadeh Jefreh

Islamic Azad University Ahvaz Branch

Mitra Tadayon

Ahvaz Jondishapour University of Medical Sciences

Mohammad Hossein Haghighizadeh

Ahvaz Jondishapour University of Medical Sciences

\section{Research article}

Keywords: Menopause, Hot Flashes frequency, Hot flash severity, Night Sweats, Cognitive-Behavioral Therapy

Posted Date: June 17th, 2020

DOI: https://doi.org/10.21203/rs.3.rs-32208/v1

License: (c) (i) This work is licensed under a Creative Commons Attribution 4.0 International License. Read Full License 


\section{Abstract}

Background: Hot flash and night sweat (HF/NS) are the most common complication in menopause that affects the quality of life of women. The present study was conducted with the aim of comparing the effectiveness of the phone with face-to-face counseling based on cognitive-behavioral therapy for vasomotor symptoms of postmenopausal women.

Methods: The present study was a randomized clinical trial. In this study, 40 eligible postmenopausal women were randomly assigned to one of face-to-face or phone counseling methods using the block randomization. Six counseling sessions were weekly held for each person and women requested to record their hot flashes and night sweat in a diary. Data were analyzed using chi-square, ANCOVA, and independent t-test.

Results: Thirty- six women completed the study. Women in two groups showed a significant improvement in the frequency, severity, and duration of hot flashes and the frequency and severity of night sweats after the intervention $(P<0.001)$. Weekly means of hot flashes and night sweats, decreased after the intervention in both groups (face-to-face group: HF frequency from $31.92 \pm 7.98$ to $18.83 \pm 7.35$, HF severity from $2.24 \pm 0.28$ to $1.21 \pm 0.23$, HF duration from $4.22 \pm 1.17 \mathrm{~min}$ to $2.79 \pm 0.91 \mathrm{~min}$, NS frequency from $2.34 \pm 0.31$ to $1.21 \pm 0.24$ and NS severity from $1.70 \pm 0.34$ to $1.03 \pm 0.29$ and also in phone counseling group: HF frequency from $33.32 \pm 7.77$ to $19.53 \pm 7.7$, HF severity from $2.23 \pm 0.24$ to $1.20 \pm 0.18$, HF duration from $4.29 \pm 1.23 \mathrm{~min}$ to $2.68 \pm 0.95 \mathrm{~min}$, NS frequency from $2.33 \pm 0.31$ to $1.14 \pm 0.16$ and NS severity from $1.59 \pm 0.34$ to $1.01 \pm 0.30$ ). There was no significant difference between groups after the intervention in terms of HF frequency, severity, and duration, as well as NS frequency, and severity $(p>0.05)$.

Conclusion: Based on the results of this study, using of face-to-face and phone counseling methods based on cognitive-behavioral therapy had a similar effect on the reducing of frequency, severity and duration of hot flashes as well as the frequency and severity of night sweats. Using phone counseling in women who have difficulty to attend the clinic is recommended.

Trial registration number: IRCT20180918041065N1 Website: https://www.irct.ir/login

\section{Background}

Menopause is a natural and physiological phenomenon in woman's life that occurs in the mid or late middle age (about 45 to 55 years of age) (1). It is associated with complications such as hot flashes, night sweats, mood changes, sleep disorders, and changes in sexual desire and sexual function (2). It can cause great and disabling stress in a person $(3,4)$. The hot flash is the most common complication of this period and is the most common cause of postmenopausal women referring to treatment clinics. Hot flash begins with the transition to menopause and it is characterized by periodic increasing of body temperature, a sudden sweat along with shivering, palpitation and anxiety, which last from several seconds to several minutes, and rarely lasts for an hour and its frequency is between 5 and 10 times per s 67-82\% (7), 70-85\% in Europe (8), and 62.5- 
$79.9 \%$ in Iran (9). It is problematic for about $20-25 \%$ of women. Stress, increased central body temperature, drinking hot beverages, alcohol, physical activity, and emotional reactions can exacerbate hot flashes (10). There are a variety of therapies to control this complication. Hormone therapy is an effective method to reduce hot flashes. However, the results of women's health studies by the National Institutes of Health showed that there is a risk of breast cancer, thromboembolic complications, stroke and heart diseases in women receiving hormone therapy (11). As a result, the use of this method has dropped since 2003 (10). Since non-hormonal mechanisms play a major role in hot flushes pathophysiology, use of new non-drug therapies such as counseling, complementary and alternative therapies (CAM), including medicinal herbs (phytoestrogens), exercise and nutrition, respiratory and relaxation techniques is being studied by researchers $(12,13)$.

In a study conducted by Bahri et al (2017) in Gonabad, $51.7 \%$ of postmenopausal women were looking for treatment of menopausal symptoms, which hormone therapy (59.5\%) had the highest frequency and acupuncture (2.9\%) had the lowest frequency (14). In the study conducted by Obermeyer (2005), two thirds of Spanish women followed the treatment of menopausal symptoms, of which $10 \%$ used hormone therapy and one fifth of them used complementary and alternative medicine therapies (15). In a study conducted by Lunny et al. (2010), the rate of postmenopausal women, use of complementary and alternative medicine was reported $91 \%$ (16). Astrand et al found that relaxation techniques are significantly associated with the reduced hot flashes (17). Counseling, especially the cognitive-behavioral approach, which is one of the practical methods, is nowadays proposed for women to cope with hot flashes (10). It helps patients identify and correct the distorted thinking patterns and inefficient behavior (18). The counseling is performed in a variety of methods, including face-to-face, phone counselling, video communication, and use of an e-mail (19). In this regard, phone counseling is very useful and inexpensive (20). It is also a valid and reliable method to treat and follow up some diseases (21). The study conducted by Stefanopoulou et al. (2013) showed that cognitive-behavioral therapy by self-help phone counseling led to a significant reduction in the severity and frequency of hot flashes and night sweats in postmenopausal women (22). The results of a study conducted by Larroy et al. (2015) in Spain showed that using cognitive-behavioral techniques led to a significant reduction in women's menopausal hot flashes, depression and anxiety (23). The results of a study conducted by Green et al (2013) in Canada showed a reduction in hot flushes in women receiving the cognitive-behavioral therapy (24). Since counseling is one of the appropriate methods for treatment of menopause symptoms, but the best method of performance has not been discovered yet. Therefore, this study was conducted to compare the effect of face-to-face and phone counseling based on cognitive behavioral therapies on hot flashes in postmenopausal women.

\section{Methods}

The present study was a parallel randomized controlled clinical trial. The aim of this study was to compare the effects of face-to-face with phone counseling based on cognitive-behavioral therapy of hot flashes in postmenopausal women. The design of this study was approved by the Ethics Committee of 
in the Iranian registry for clinical trials with reference number (IRCT20180918041065N1). All women provided written informed consent prior to data collection. The data collection started in December 2018 and completed in March 2019.

A sample of 40 people was selected based on inclusion and exclusion criteria of study for postmenopausal women who admitted to the clinic of the Ahvaz Imam Khomeini Hospital with complain of hot flashes. The sample of 40 was considered according to $95 \%$ confidence interval and the power of the study was set at $90 \%$ (10). We considered $10 \%$ for drop-out.

The inclusion criteria included women aged 40 to 60 years with normal menopause, a minimum of 1 year and a maximum of 5 years passed from their menopause, having at least 20 hot flushes per week for at least one month, literate women, obtaining a score more than one in the Kupperman hot flash index). The exclusion criteria included known psychological and physical illness, drug abuse, and the use of medicine for hot flash. Eligible women were screened through phone call and a brief explanation of the research was provided for them, its objectives and the way of its performing. The researcher ensured the women that the information will remain confidential.

Eligible women asked to complete the demographic questionnaires and the Kupperman Index and a they received a diary to record the daily symptoms of hot flushes and night sweats. Out of 48 eligible women invited to the clinic, 40 provided consent and signed the consent form. After performing the interviews and the necessary examinations, the participants were randomly assigned to one of two groups of phone or face-to-face counseling using the block randomization with the block size 4 and allocation ratio 1:1. Phone counseling group received 6 weekly 30-40-minute counseling based on cognitive-behavioral therapy. Due to the need for direct training of breathing and relaxation techniques and the way of completing diary and monitoring the way of performing the tasks and being ensured that they are performed correctly, the sessions 1 and 4 were held in person and another 4 sessions were held by phone. The face-to-face counseling group also received 6 weekly 30-60-minute cognitive-behavioral counseling sessions. The members of both groups received a CD on breathing and relaxation techniques for daily practice. Kupperman index was completed at the start of the study, immediately after 6 sessions, and 8 weeks after the completion of intervention for both groups.

Due to the nature of this study, blinding of researchers and participants was not possible, but after randomization, the codes dedicated in each participant were kept with the secretary of the clinic for preserving allocation concealment. Therefore, none of the participants and researcher were not aware of the allocation order until the commencement of intervention.

\section{Statistics}

All data entered SPSS version 20. For continuous data independent t-test and for categorical data, the chisquare test was used. The paired t-test was used for comparison before and after intervention. An 
ANCOVA was used for variables that showed statistical differences before intervention. $\mathrm{P}<0.05$ considered significant.

\section{Results}

In this study, out of 40 subjects, 36 subjects completed the study in two face-to-face and phone counseling groups (Fig. 1). The results of the comparisons show that therapeutic groups do not differ significantly in terms of age (year), menopausal time (year), body mass index, education level, economic status, and other demographic characteristics (Table 1).

The results of this study showed that there is a significant difference between two groups of phone and face-to face regarding frequency, severity, duration of hot flashes, number, and severity of night sweats before and after intervention and in the follow-up period $(p<0.001)$. Weekly means of hot flashes and night sweats, decreased after the intervention in both groups (face-to-face group: HF frequency from $31.92 \pm 7.98$ to $18.83 \pm 7.35$, HF severity from $2.24 \pm 0.28$ to $1.21 \pm 0.23$, HF duration from $4.22 \pm 1.17$ min to $2.79 \pm 0.91 \mathrm{~min}$, NS frequency from $2.34 \pm 0.31$ to $1.21 \pm 0.24$ and NS severity from $1.70 \pm 0.34$ to 1.03 \pm 0.29 and also in phone counseling group: HF frequency from $33.32 \pm 7.77$ to $19.53 \pm 7.7$, HF severity from $2.23 \pm 0.24$ to $1.20 \pm 0.18$, HF duration from $4.29 \pm 1.23 \mathrm{~min}$ to $2.68 \pm 0.95 \mathrm{~min}$, NS frequency from $2.33 \pm 0.31$ to $1.14 \pm 0.16$ and NS severity from $1.59 \pm 0.34$ to $1.01 \pm 0.30$ ). The between- group comparison of groups using independent t-test showed that there was no significant difference between two groups regarding mentioned variables (Table 2). 
Table 1

Demographic characteristics of participants in two study groups

\begin{tabular}{|c|c|c|c|c|}
\hline \multirow{3}{*}{\multicolumn{2}{|c|}{ VARIABLES }} & Face-to-face group & Phone group & \multirow[t]{3}{*}{ P-value } \\
\hline & & $18=n$ & $18=n$ & \\
\hline & & \multicolumn{2}{|l|}{ Mean \pm SD } & \\
\hline \multicolumn{2}{|l|}{ Age (y) } & & $52.33 \pm 3.39$ & 0.576 \\
\hline \multicolumn{2}{|c|}{ Time passed from the last menstruation (year) } & $3.3 \pm 1.27$ & $3.1 \pm 1.32$ & 0.612 \\
\hline & & \multicolumn{2}{|l|}{$\mathrm{N}(\%)$} & \\
\hline \multirow[t]{4}{*}{ Education } & Elementary & $5(27.8)$ & $5(27.8)$ & \multirow[t]{4}{*}{0.924} \\
\hline & secondary & $8(44.4)$ & $7(38.9)$ & \\
\hline & High school & $5(27.8)$ & $6(33.3)$ & \\
\hline & Academic & $5(27.8)$ & $5(27.8)$ & \\
\hline \multirow[t]{2}{*}{ Employment } & Housewife & 15(83.3) & 16(88.9) & \multirow[t]{2}{*}{0.630} \\
\hline & Employed & $3(16.7)$ & $2(11.1)$ & \\
\hline \multirow[t]{3}{*}{ Income adequacy } & Yes & 2(11.1) & $3(16.7)$ & \multirow[t]{2}{*}{0.713} \\
\hline & No & $1(5.6)$ & 2(11.1) & \\
\hline & To some extent & 15(83.3) & $13(72.2)$ & \\
\hline
\end{tabular}

Tables 2: Frequency, severity and duration of hot flashes, and the frequency and severity of night sweats in two groups of face-to-face and phone counseling 


\begin{tabular}{|c|c|c|c|c|c|}
\hline Variable & & $\begin{array}{l}\text { Face-to-face } \\
\text { counseling group } \\
\mathrm{N}=18\end{array}$ & $\begin{array}{l}\text { Phone } \\
\text { counseling } \\
\text { group } \\
18=\mathrm{N}\end{array}$ & $\begin{array}{l}\text { P-value } \\
\text { Independent t- } \\
\text { test }\end{array}$ & $\begin{array}{l}\text { P-value } \\
\text { using } \\
\text { ANCOVA }\end{array}$ \\
\hline & & Mean \pm SD & & & \\
\hline \multirow[t]{3}{*}{$\begin{array}{l}\text { Frequency of } \\
\text { flashes }\end{array}$} & $\begin{array}{l}\text { Before } \\
\text { intervention }\end{array}$ & $31.92 \pm 7.98$ & $33.32 \pm 7.77$ & 0.591 & 0.662 \\
\hline & $\begin{array}{l}\text { After } \\
\text { intervention }\end{array}$ & $18.83 \pm 7.35$ & $19.53 \pm 7.7$ & 0.791 & \\
\hline & Follow up & $19.32 \pm 7.21$ & $20.09 \pm 7.84$ & 0.762 & \\
\hline \multirow[t]{3}{*}{$\begin{array}{l}\text { Severity of } \\
\text { hot flashes }\end{array}$} & $\begin{array}{l}\text { Before } \\
\text { intervention }\end{array}$ & $2.24 \pm 0.28$ & $2.23 \pm 0.24$ & 0.941 & 0.859 \\
\hline & $\begin{array}{l}\text { After } \\
\text { intervention }\end{array}$ & $1.21 \pm 0.23$ & $1.20 \pm 0.18$ & 0.809 & \\
\hline & Follow up & $1.23 \pm 0.25$ & $1.22 \pm 0.22$ & 0.853 & \\
\hline \multirow[t]{3}{*}{$\begin{array}{l}\text { Duration of } \\
\text { hot flashes }\end{array}$} & $\begin{array}{l}\text { Before } \\
\text { intervention }\end{array}$ & $4.22 \pm 1.17$ & $4.29 \pm 1.23$ & 0.858 & 0.815 \\
\hline & $\begin{array}{l}\text { After } \\
\text { intervention }\end{array}$ & $2.79 \pm 0.91$ & $2.68 \pm 0.95$ & 0.736 & \\
\hline & Follow up & $2.93 \pm 0.84$ & $2.77 \pm 0.89$ & 0.583 & \\
\hline \multirow[t]{3}{*}{$\begin{array}{l}\text { Severity of } \\
\text { night sweats }\end{array}$} & $\begin{array}{l}\text { Before } \\
\text { intervention }\end{array}$ & $2.34 \pm 0.31$ & $2.33 \pm 0.31$ & 0.937 & 0.579 \\
\hline & $\begin{array}{l}\text { After } \\
\text { intervention }\end{array}$ & $1.21 \pm 0.24$ & $1.14 \pm 0.16$ & 0.316 & \\
\hline & Follow up & $1.24 \pm 0.28$ & $1.18 \pm 0.21$ & 0.520 & \\
\hline \multirow[t]{3}{*}{$\begin{array}{l}\text { Number of } \\
\text { night sweats }\end{array}$} & $\begin{array}{l}\text { Before } \\
\text { intervention }\end{array}$ & $1.7 \pm 0.34$ & $1.59 \pm 0.34$ & 0.346 & 0.574 \\
\hline & $\begin{array}{l}\text { After } \\
\text { intervention }\end{array}$ & $1.03 \pm 0.29$ & $1.01 \pm 0.30$ & 0.851 & \\
\hline & Follow up & $1.2 \pm 0.28$ & $1.0 \pm 0.28$ & 0.826 & \\
\hline
\end{tabular}

\section{Discussion And Conclusion}

This study designed to compare the effect of phone counseling with face-to face counseling based on cognitive behavioral therapy on hot flashes and night sweats of postmenopausal women.

Hot flash is the most common and most annoying complication in postmenopausal women, which Loading [MathJax]/jax/output/CommonHTML/fonts/TeX/fontdata.js aches, including cognitive-behavioral therapy, 
are suggested to improve this complication. The results of statistical comparisons showed that two therapeutic groups did not differ in the factors affecting hot flashes. Thus, any change in the symptoms of the participants in the two groups is related to the use of CBT. The results of this study suggest the significant effect of different methods of cognitive-behavioral therapy on reducing vasomotor symptoms in postmenopausal women. Hardy et al (2018) found that cognitive-behavioral therapy in a self-help manner significantly reduced the severity and frequency of hot flushes and night sweats in 6 and 20 weeks after the intervention (25). Ayers et al (2013) also found that cognitive-behavioral therapy had a significant effect on reducing the severity of hot flashes and night sweats in both self-help and group manners (10). The results of the research conducted by Mann (2012) showed that the use of cognitivebehavioral therapy could significantly reduce the severity of hot flashes and night sweats in postmenopausal women suffering from cancer (18).

In recent years, counseling has been proposed as one of the methods to help women to cope with hot flashes and cognitive-behavioral therapy is one of the practical counseling methods in this area (10). This approach can be used as an intervention method to reduce the menopause complications of helping patients identify distorted thinking patterns and ineffective behaviors through regular discussions and structured behavioral assignments (18). It is also looking forward presenting adaptive coping responses and controlling negative emotions by correcting false interpretations, guiding negative self-talks, correcting irrational patterns of thinking and ineffective recognition (26). Several studies have reported the positive effects of the use of cognitive-behavioral therapies in health-related areas, including the reduction of menopausal symptoms. Phone counseling is one of the most useful and inexpensive methods (20), leading to economic savings, improved service quality (27), and reduced work load of the health system (28). In many advanced medical centers in the world, phone counseling is used to reduce costs and unnecessary visits. One of the disadvantages of this method is the potential risks of counseling due to the lack of visual and non-verbal communication, which causes the consultant to rely on the voice of clients rather than paying attention to the visual signs (29). The results of the present study showed that the method of providing cognitive-behavioral therapy counseling has no effect on the outcome and both face-to-face and phone methods, can be effective. Thus, considering the benefits of phone counseling, we suggest that this method can be recommended to reduce the vasomotor symptoms in postmenopausal women, who are not able to refer treatment centers in person.

Limitations of the study

In this study, the severity and frequency of hot flashes and night sweats were examined at the beginning of the study, six weeks after the intervention and eight weeks after the end of the intervention.

Assessment of frequency and severity of hot flashes and night sweats were, according to the diaries that completed by participants and may affected by recall bias.

\section{Conclusion}


According to the results of this study, the use of face-to-face and phone counseling based on cognitive behavioral therapy could significantly reduce the severity, frequency and duration of hot flashes and severity and frequency of night sweats and no significant difference was seen between the two intervention methods. Using phone counseling in women that have difficulties in attending the clinic is recommended.

\section{Abbreviations}

HF

Hot flashes

NS

Night sweats

ANCOVA

Analysis of covariance

\section{Declarations}

Ethics approval and consent to participate: The design of this study was approved by the Ethics Committee of Ahvaz Jundishapur University of Medical Sciences (IR. AJUMS.REC.2018.289). This study was registered in the Iranian registry for clinical trials with reference number (IRCT20180918041065N1). All women provided written informed consent prior to data collection.

Consent to publish: Not Applicable.

Availability of data and materials: Data of this study will be available upon the request from the corresponding author.

Competing interests: Authors declare that they do not have any conflict of interest.

Funding: This study was funded by the Ahvaz Jundishapur University of Medical Sciences. The funder does not have any role in design, data collection, data interpretation, and writing the manuscript.

Authors' contributions: NSJ, PA, MGJ, MT and MHH were responsible for the design. NSJ collected data. NSJ and MHH analyzed data. NSJ, PA and MHH interpreted data. NSJ prepared the manuscript. All authors read and approved the final version of the manuscript.

Acknowledgement: This is a master thesis of NSJ. We hereby thank all women who participated in this study and the staff of the menopause clinic of the Ahvaz University of Medical Sciences.

\section{References}

1. Van Die MD, Burger HG, Bone KM, Cohen MM, Teede HJ. Hypericum perforatum with Vitex agnusLoading [MathJax]/jax/output/CommonHTML/fonts/TeX/fontdata.js trolled trial. Menopause. 2009;16(1):63-156. 
2. Vaz AF, Conde DM, Costa-Paiva L, Morais SS, Esteves SB, Pinto-Neto AM. Quality of life and adverse events after radiotherapy in gynecologic cancer survivors: a cohort study. ARCH GYNECOL OBSTET. 2011;284(6):1523-31.

3. Saleh F, Afnan F, Ara F, Yasmin S, Nahar K, Khatun F, et al. Phytoestrogen intake and cardiovascular risk markers in Bangladeshi postmenopausal women. MMJ. 2011;20(2):219-25.

4. Speroff L, Fritz MA. Clinical gynecologic endocrinology and infertility: Lippincott Williams \& Wilkins; 2005.

5. Gentry L, Slupik R. The Everything menopause.Book 2003.(Everything):21-49.

6. Lobo RA. Treatment of the postmenopausal woman: basic and clinical aspects: Academic Press, Elsevier; 2007.

7. Tempfer CB, Bentz E-K, Leodolter S, Tscherne G, Reuss F, Cross HS, et al. Phytoestrogens in clinical practice: a review of the literature. Fertility Sterility. 2007;87(6):1243-49.

8. Shojaeian Z, Abedian Z, Mazloom S. Effect of hormone therapy on depression in menopausal women (dissertation). Sabzevar Uni Med Sci: 2007;12(1):37-43.[In Persian].

9. Ayers B, Smith M, Hellier J, Mann E, Hunter MS. Effectiveness of group and self-help cognitive behavior therapy in reducing problematic menopausal hot flushes and night sweats (MENOS 2): a randomized controlled trial. Menopause. 2012;19(7):749-59.

10. Theroux R. Women's decision making during the menopausal transition. J Am Acad Nurse Pract. 2010;22(11):612-21.

11. Hunter MS, Liao KLM. Evaluation of a four-session cognitive-behavioural intervention for menopausal hot flushes. BrJHealth Psychol. 1996;1(2):25-113.

12. Honarjoo M, Tadayon M, Abedi P. Effect of Oral Antyoxidants Supplement (Vitamin E and Omega3) on Frequency and Intensity of Hot Flashes in Postmenopausal Women. IJOGI. 2015;17:133:22-8.

13. Bahri N, Pourali L, Esmaeeli H. Application of Various Menopausal Symptoms Treatment Options and its Related Factors. Gonabad. 2016;26:1-8.

14. Obermeyer CM, Reher D, Alcala LC, Price K. The menopause in Spain: results of the DAMES (Decisions At MEnopause) study. Maturitas. 2005;52(43):8-190.

15. Lunny CA, Fraser SN. The use of complementary and alternative medicines among a sample of Canadian menopausal-aged women. J Midwifery Women's Health. 2010;55(4):335-43.

16. Astrand L, Nedstrand E. Effects of applied relaxation on vasomotor symptoms in postmenopausal women: a randomized controlled trial. Menopause. 2013;20(4):401-8.

17. Mann E, Smith MJ, Hellier J, Balabanovic JA, Hamed H, Grunfeld EA, et al. Cognitive behavioural treatment for women who have menopausal symptoms after breast cancer treatment (MENOS 1): a randomised controlled trial. LANCET Oncol. 2012;13(3):309-18.

18. Aghababaei N. Telephone Counseling; Performance and functionality. Pajohesh va Hozeh. 2007;32:95-105..[In Persian]. 
19. Bunn F, Byrne G, Kendall S. The effects of telephone consultation and triage on healthcare use and patient satisfaction: a systematic review. Br J Gen Pract. 2005;55(521):956-61.

20. Remschmidt $H$, Hirsch $O$, Mattejat F. Reliability and validity of evaluation data collected by telephone. Zeitschrift fur Kinder-und Jugendpsychiatrie Psychotherapie. 2003;31(1):35-49.

21. Stefanopoulou E, Hunter MS. Telephone-guided self-help cognitive behavioural therapy for menopausal symptoms. Maturitas. 2014;77(1):73-7.

22. Larroy García C, Marín Martín C, Gutiérrez Gómez-Calcerrada S. Effects of Cognitive-Behavioral techniques on hot flushes, depression and anxiety related to menopause in Spanish women.2015.

23. Green SM, Haber E, McCabe RE, Soares CN. Cognitive-behavioral group treatment for menopausal symptoms: a pilot study. Arch Womens Ment Health. 2013;16(4):325-32.

24. Hardy C, Griffiths A, Norton S, Hunter MS. Self-help cognitive behavior therapy for working women with problematic hot flushes and night sweats (MENOS@ Work): a multicenter randomized controlled trial. Menopause. 2018;25(5):508-19.

25. Leichsenring F, Salzer S, Beutel ME, Herpertz S, Hiller W, Hoyer J, et al. Psychodynamic therapy and cognitive-behavioral therapy in social anxiety disorder: a multicenter randomized controlled trial. Am J Psychiatry. 2013;170(7):759-67.

26. Wegner SE, Humble CG, Feaganes J, Stiles AD. Estimated savings from paid telephone consultations between subspecialists and primary care physicians. Pediatrics. 2008;122(6):1136-40.

27. Leibowitz R, Day S, Dunt D. A systematic review of the effect of different models of after-hours primary medical care services on clinical outcome, medical workload, and patient and GP satisfaction. Fam Pract. 2003;20(3):311-7.

28. Huibers L, Keizer E, Giesen P, Grol R, Wensing M. Nurse telephone triage: good quality associated with appropriate decisions. Fam Pract. 2012;29(5):547-52.

29. 29. Huibers L, Keizer E, Giesen P, Grol R, Wensing M. Nurse telephone triage: good quality associated with appropriate decisions. Family Practice. 2012; 29(5): 547 - 52.

\section{Figures}




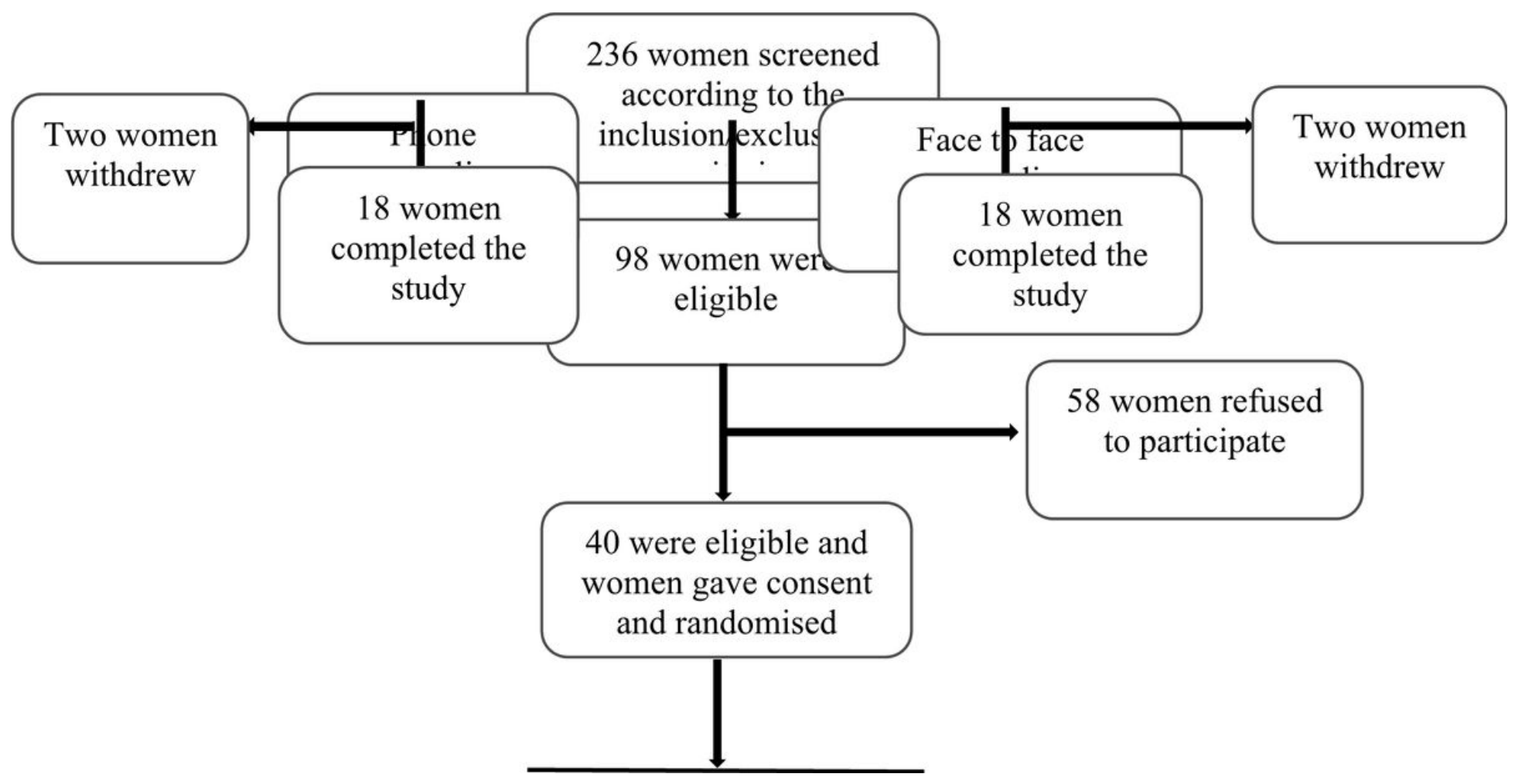

Figure 1

Flow-diagram of recruitment and retention of participants in the study

\section{Supplementary Files}

This is a list of supplementary files associated with this preprint. Click to download.

- supplement4.doc 